\title{
Postvoid residual urine in the evaluation of men with benign prostatic hyperplasia
}

\author{
J. L. H. Ruud Bosch \\ Department of Urology, H-1073, Erasmus University and Academic Hospital, Dr. Molewaterplein 40, NL-3015 GD Rotterdam, \\ The Netherlands
}

\begin{abstract}
Summary. Traditionally, the measurement of postvoid residual urinary volume (PVR) has played a prominent role in the evaluation of men with symptoms suggestive of benign prostatic hyperplasia (BPH). This article reviews current opinions about the cause of PVR, methods and accuracy of measurement, correlations between PVR and symptoms as well as physiologic measures of BPH and the role of PVR determination in the evaluation of BPH patients. Community-based data obtained on PVR in men aged between 55 and 74 years in the city of Rotterdam (The Netherlands) are reported.
\end{abstract}

The International Continence Society Committee on Standardization of Terminology [3] defines residual urine as the volume of fluid remaining in the bladder immediately following the completion of micturition. The committee emphasizes that unrepresentative results may be obtained when voiding has to occur in unfamiliar surroundings or on command with a partially filled or overfilled bladder. The interval between voiding and residual urinary volume measurement has to be recorded, although there should ideally be no interval at all. This is particularly important if the patient is in a diuretic phase.

Traditionally, the measurement of postvoid residual urinary volume (PVR) has been an important test in the evaluation and follow-up of patients with benign prostatic hyperplasia (BPH). Presently, there is no agreement as to the place and value of PVR measurement in the diagnostic evaluation of BPH patients. During the "Second International Consultation on Benign Prostatic Hyperplasia," a consensus committee has formulated recommendations concerning the diagnostic workup of patients presenting with symptoms suggestive of prostatism. Tests were classified as mandatory, recommended, or optional. This committee recommended the measurement of PVR in the diagnostic workup of patients with symptoms of prostatism [10]. Clinical practice guidelines for the United States have been issued by the Benign Prostatic Hyperplasia Guideline Panel. This panel considered the measurement of PVR to be an optional test [6].

\section{The cause of PVR}

Residual urine is related to bladder-outflow obstruction. Other causes of incomplete emptying include neurogenic dysfunction of the lower urinary tract and detrusor failure due to pharmacologic causes, overdistension of the bladder not related to outflow obstruction, and idiopathic cases.

A given bladder with a certain premicturition volume has a well-defined myogenic capability to generate power. This mechanical power of the bladder contraction shows itself by yielding a given flow rate in combination with a certain detrusor pressure. There is a trade-off between flow rate and detrusor pressure; in the case of infravesical obstruction, the voiding pressure increases while the flow rate decreases [12]. The amount of work needed for the bladder to empty completely is determined by the voiding pressure and the bladder volume [21]. The amount of energy that a certain bladder can generate is limited.

In animal experiments, Levin et al [17] have shown the biphasic nature of the bladder contraction: an initial phasic contractile response, which determines the pressure response, is followed by a plateau phase that determines the ability to empty. The initial phasic response appears to be related to the intracellular adenosine triphosphate (ATP) concentration, whereas the ability to sustain a contraction may be linked to active mitochondrial respiration. Outlet obstruction has been shown to cause a marked increase in anaerobic metabolism in the rabbit bladder [16]. Malkowicz et al. [18] have shown in the whole-rabbit-bladder model of obstruction that the ability of the bladder to empty is impaired to a greater degree than is its ability to generate pressure. If the bladder runs out of energy before it is empty, the detrusor contraction fades away prematurely and a certain amount of residual urine is the consequence of this decompensation.

\section{Measurement of PVR: methods and reproducibility}

PVR measurement can be performed by several methods. In-and-out catherization has been considered to be the most accurate technique. However, Stoller and Millard 
[23] have shown that the bladder was actually not empty in $26 \%$ of patients catheterized by urological nurses. Even after further instructions to improve the technique, the bladder was not empty in $14 \%$ of the patients.

The noninvasive measurement by transabdominal ultrasound is presently the method preferred by most urologists and their patients. Birch et al. [7] compared five different formulae that can be used to calculate PVR on the basis of measurements made by ultrasound. They concluded that the concordance between the methods was 93.6\% and, consequently, that there was little to choose between. Roehrborn and Peters [20] used a further formula for volume calculation; volumes determined using the ellipsoid formula $(0.52 \times$ width $\times$ height $\times$ length $)$ showed an excellent correlation with those measured by catheterization $(r=0.982 ; P<0.001)$. These authors also noted that the error rate was highest in the low-volume range but that the absolute difference between actual and estimated PVR values was always low.

Some clinicians [6] doubt the value of PVR measurements because of the lack of reproducibility of this test. Physiologic measures always exhibit some degree of intraindividual variation. In humans there is no fixed heart rate or blood pressure, and it would indeed be very "unphysiologic" if there were no variation in PVR. Birch et al. [7] reported that of 30 men, $66 \%$ had significant variations in PVR when 3 scans were done on the same day; however, in only $8 \%$ of the men were all 3 measurements statistically significantly different. All patients in this study had residual urinary volumes on all scans, which shows that this population was a very selected one. Furthermore, the authors do not clearly state whether scans were done immediately after voiding but mention that "further scans were timed at $09.00,13.00$ and $16.30 \mathrm{hrs}$. [sic] or as near to those times as possible." Bruskewitz et al. [9] found similar variations in PVR measurements in 47 men prior to prostatectomy. These authors mention neither the method of residual urinary volume determination, the interval between the termination of voiding and the PVR measurements, nor the length of the period over which the measurements were performed. Further and better designed studies on the variability of PVR measurement are certainly needed since the two above-mentioned studies are inconclusive for methodologic reasons.

\section{Which PVR value is normal or abnormal?}

Hinman and Cox [13] recognize that there is always some residual urine after voiding (wetness of the bladder mucosa); they studied four normal men to determine the minimal possible amount of residual urine. In these men the mean minimal volume of residual urine was $0.53 \mathrm{ml}$ (range, 0.09-2.34 ml). Di Mare et al. [11] have shown that $78 \%$ of normal men have residual urinary volumes of $<5$ $\mathrm{ml}$ and that $100 \%$ have a PVR value of $<12 \mathrm{ml}$.

In Rotterdam (The Netherlands), community-based data on PVR and symptoms of BPH were collected in a sidestudy of a randomized pilot study on the value of screening versus no screening for prostate cancer [8]. Only men in whom prostate cancer had been excluded by appropri-
Table 1. Mean and median values and interquartile ranges obtained for PVR in four consecutive 5-year age intervals in a community-based population of men without prostate cancer or a history of prostate operation

\begin{tabular}{lrlll}
\hline $\begin{array}{l}\text { Age } \\
\text { (years) }\end{array}$ & $\begin{array}{l}\text { Number } \\
\text { of men }\end{array}$ & \multicolumn{2}{l}{ PVR $(\mathrm{ml})$} & \\
\cline { 3 - 5 } & & Mean $\pm \mathrm{SE}$ & Median & $\begin{array}{l}\text { Interquartile } \\
\text { range }\end{array}$ \\
\hline $55-59$ & 76 & $22( \pm 5)$ & 0 & $0-17$ \\
$60-64$ & 100 & $17( \pm 5)$ & 0 & $0-0$ \\
$65-69$ & 90 & $25( \pm 5)$ & 0 & $0-35$ \\
$70-74$ & 60 & $31( \pm 7)$ & 0 & $0-53$ \\
Total & 326 & $23( \pm 3)$ & 0 & $0-21$ \\
\hline
\end{tabular}

Table 2. Percentage of men with a PVR value of less than or equal to $50 \mathrm{ml}$ and percentage of men with a value ranging between 50 and $100 \mathrm{ml}$ as determined by age in a community-based population of men without prostate cancer or a history of prostate operation

\begin{tabular}{lrll}
\hline Age (years) & $n$ & $\begin{array}{l}\% \text { With PVR } \\
\leq 50 \mathrm{ml}\end{array}$ & $\begin{array}{l}\% \text { With PVR } \\
50-100 \mathrm{ml}\end{array}$ \\
\hline $55-59$ & 76 & $88 \%$ & $1 \%$ \\
$60-64$ & 100 & $88 \%$ & $5 \%$ \\
$65-69$ & 90 & $82 \%$ & $12 \%$ \\
$70-74$ & 60 & $70 \%$ & $20 \%$ \\
Total & 326 & $83 \%$ & $9 \%$ \\
\hline
\end{tabular}

ate screening tests and who had not previously undergone a prostate operation were included in this side study. The 374 consecutive men enrolled were part of the community-based population of men aged 55-74 years who had been randomly assigned to undergo tests to screen for prostate cancer. These men were not specifically asked to come to the clinic with a full bladder but were instructed to wait for the flowmetry (using a Dantec Urodyn 1000 flowmeter) and not to void before that time.

Within 10 min of the termination of voiding, the PVR value (expressed in milliliters) was computed using an Aloka machine with a $3.5-\mathrm{MHz}$ hand-held probe using the formula $\pi / 6 \times($ width $) \times$ (height $) \times($ depth $)$. The 374 men in whom a PVR determination was planned were asked to void in the flowmeter, but $48(13 \%)$ could not do so at that particular point in time. The determination of residual urine by ultrasound was performed only in those men who could void in the flowmeter $(n=326)$. Symptoms of prostatism were assessed using the American Urologic Association (AUA)-7 symptom index [4]. Table 1 shows the mean and median values and interquartile ranges obtained for PVR in four consecutive 5-year age intervals (range, 55-74 years). The increase in mean residual urinary volume with age was statistically significant $(P=0.02)$.

The percentages of men with a PVR value of $\leq 50 \mathrm{ml}$ and of $50-100 \mathrm{ml}$ as determined in the different age intervals is shown in Table 2 . The percentage of men with a PVR value of $>50 \mathrm{ml}$ shows a statistically significant increase with age $(P=0.01)$. 
Correlations with symptoms and other physiologic measures

Of the 326 evaluable men in the Rotterdam study, 55 had a residual urinary volume of $>50 \mathrm{ml}$. However, in response to the AUA-7 question, "Over the past month, how often have you had a sensation of not emptying your bladder completely after you finished urinating?", 31 (56\%) of these men answered "never" and only 11 men (20\%) responded that this was the case "about half the time or more often." On the other hand, of the 271 men with a PVR value of $\leq 50 \mathrm{ml}, 14(5 \%)$ answered "more than half the time or always." The score on the above-mentioned AUA-7 question about incomplete emptying was weakly correlated with PVR $(r=0.14, P=0.01)$. In this community-based population, weak correlations were also found between PVR and the total AUA symptom score $(r=0.25, P<0.05)$, maximal flow rate $(r=-0.18 ; P 0.05)$, prostate volume $(r=0.21, P<0.05)$, and age $(r=0.12 ; P<0.05)$, respectively. In a group of men included in the BPH treatmentoutcome pilot study (BTOPS), equally poor correlations were found between baseline PVR values and the AUA symptom score $(r=0.01 ; P=0.84)$, peak flow rate $(r=$ $-0.19 ; P=0.009)$, average flow rate $(r=-0.19 ; P=0.009)$, and prostate size $(r=0.07 ; P=0.35)$, respectively [5].

\section{PVR in classification of BPH and associated urodynamic findings}

In the past, patients presented more often with the severe life-threatening manifestations of BPH. Since these complications were often related to retention with upper-tract dilatation and renal failure, it is not surprising that residual urine gained much emphasis in attempts to classify BPH according to different grades of severity [22]. Presently, patients rarely exhibit these severe complications and treatment aims at improvement of the quality of life and at prevention of lower-urinary-tract deterioration. Many men request evaluation and treatment of symptomatic BPH in the absence of residual urine. Although Jones and George [15] have postulated that hydronephrosis occurs only in a significant number of patients with socalled high-pressure chronic retention due to reduced bladder compliance during the filling phase, it is actually unknown as to which and how many men would progress to upper-tract dilatation and renal failure.

\section{PVR as an indication for treatment and as a predictor of treatment outcome}

Large studies of the urodynamic results of operative treatment for BPH have shown that the volume of residual urine significantly decreases after the operation. Abrams et al. [2] showed in a series of 152 men treated by transurethral resection of the prostate that the mean PVR value decreased from 106 to $28 \mathrm{ml}$. Neal et al. [19] reported a decrease from an average of $196 \mathrm{ml}$ to $67 \mathrm{ml}$ in a series of 207 patients. Residual urinary volume was not among the factors that seemed to predict for a poor or good outcome after the operation in these two studies. Jensen et al. [14] studied the outcome of surgery in 120 men with prostatism. They found that after pressure-flow studies, PVR was the second best predictor of outcome, although none of the patients who failed could be predicted by preoperatively determined parameters.

Since the outcome does not seem to be influenced by the preoperative presence or absence of PVR, it is difficult to accept the presence of PVR as an indication for treatment. The presence of PVR has traditionally been thought to be associated with an increased risk for urinary tract infection. Bruskewitz et al. [9] could not find an association between PVR and a history of urinary tract infection in a limited group of 47 patients. These authors also concluded that there was no correlation between the preoperative PVR value and the postoperative outcome. However, it should be noted that only 9 of the 47 patients evaluated in this study had PVR values exceeding $50 \mathrm{ml}$ at all measurements; furthermore, of these 9 patients, only 4 had PVR values exceeding $100 \mathrm{ml}$ at all measurements. This indicates that this patient population was most probably too small and that the range of the variable of interest was too restricted to justify these conclusions. Abrams et al. [1] have shown that patients with a significant amount of residual urine who have low bladder pressures at cystometric capacity and during voiding have a poor prognosis with regard to normalization of micturition.

The most relevant finding from a clinical point of view is not the exact volume but the presence or absence of a significant amount of residual urine. A lack of postvoid residual urine is a finding of clinical significance because it indicates that the patient can efficiently empty his bladder, although it does not exclude bladder-outflow obstruction [3]. The presence of residual urine may be of clinical significance for at least two reasons: first, the risk of urinary tract infection may be increased, although further studies are needed to establish this relationship firmly, and second, a significant amount of residual urine decreases the functional bladder capacity, which may lead to symptoms of frequency, urgency, and nocturia. In cases of very high residual urinary volume, overflow incontinence can occur. Community-based data indicate that significant amounts of residual urine $(>50 \mathrm{ml})$ occur in $<18 \%$ of men aged between 55 and 69 years.

\section{References}

1. Abrams PH, Dunn M, George N (1978) Urodynamic findings in chronic retention of urine and their relevance to results of surgery. BMJ 2:1258-1260

2. Abrams PH, Farrar DJ, Turner-Warwick RT, Whiteside CG, Feneley RCL (1979) The results of prostatectomy: a symptomatic and urodynamic analysis of 152 patients. J Urol 121: 640-642

3. Abrams PH, Blaivas JG, Stanton SL, Andersen JT (1991) Standardization of terminology of lower urinary tract function. In: Krane RJ, Siroky MB (eds) Clinical neurourology. Little, Brown and Company, Boston, pp 651-669

4. Barry MJ, Fowler FJ, O'Leary MP, Bruskewitz RC, Holtgrewe HL, Mebust WK, Cockett ATK, Measurement committee of the American Urological Association (1992) The American Urological Association symptom index for benign prostatic hyperplasia. J Urol 148: 1549-1557 
5. Barry MJ, Cockett ATK, Holtgrewe HL, McConnell JD, Sihelnik SA, Winfield HN (1993) Relationship of symptoms of prostatism to commonly used physiological and anatomical measures of the severity of benign prostatic hyerplasia. J Urol $150: 351-358$

6. Benign Prostatic Hyperplasia Guideline Panel (1994) Benign prostatic hyperplasia: diagnosis and treatment (clinical practice guideline 8). Agency for Health Care Policy and Research, Rockville, pp 42-46

7. Birch NC, Hurst G, Doyle PT (1988) Serial residual volumes in men with prostatic hypertrophy. Br J Urol 62:571-575

8. Bosch JLHR, Niemer AQHL, Kirkels WJ, Schröder FH (1994) Signs and symptoms of benign prostatic hyperplasia in men screened for prostatic carcinoma. In: Kurth K, Newling DWW (eds) Benign prostatic hyperplasia - recent progress in clinical research and practice. Wiley-Liss, New York, pp 97-107

9. Bruskewitz RC, Iversen P, Madsen PO (1982) Value of postvoid residual urine determination in evaluation of prostatism. Urology 20:602-604

10. Cockett ATK, Aso Y, Denis L, Murphy G, Khoury S, Abrams P, Barry M, Carlton GE, Fitzpatrick J, Gibbons R, Griffiths K, Hald T, Holtgrewe L, Jardin A, McConnell J, Mebust W, Roehrborn C, Smith P, Steg A, Walsh P, members of the committees (1991) Recommendations of the International Consensus Committee concerning diagnostic work-up of patients presenting with symptoms suggestive of prostatism. In: Cockett ATK, Aso Y, Chatelain C, Denis L, Griffiths K, Khoury S, Murphy G (eds) Proceedings of the International Consultation on Benign Prostatic Hyperplasia. WHO, Geneva, pp 51-62

11. Di Mare JR, Fish SR, Harper JM, Politano VA (1966) Residual urine in normal male subjects. J Urol 96:180-181

12. Griffiths DJ (1988) Mechanics of micturition. In: Yalla SV, McGuire EJ, Elbadawi A, Blaivas JG (eds) Neurourology and urodynamics-principles and practice. MacMillan, New York, pp 96-105
13. Hinman F, Cox CE (1967) Residual urine volume in normal male subjects. J Urol 97:641-645

14. Jensen K-M, Jorgensen JB, Mogensen P (1988) Urodynamics in prostatism. III. Prognostic value of medium-fill water cystometry. Scand J Urol Nephrol 114 [Suppl]:78-83

15. Jones DA, George NJR (1992) Interactive obstructive uropathy in man. Br J Urol 69:337-345

16. Kato K, Tong-Long Lin A, Haugaard N, Wein AJ, Levin RM (1990) Effects of outlet obstruction on glucose metabolism of the rabbit urinary bladder. J Urol 143:844-847

17. Levin RM, Ruggieri MR, Gill HS, Haugaard N, Wein AJ (1987) Studies on the biphasic nature of urinary bladder contraction and function. Neurourol Urodyn 6:339-350

18. Malkowicz SB, Wein AJ, Elbadawi A, Arsdalen K van, Ruggieri MR, Wein AJ, Levin RM (1986) Acute biochemical and functional alterations in the partially obstructed rabbit urinary bladder. J Urol 136:1324-1329

19. Neal DE, Ramsden PD, Sharples L, Smith A, Powell PH, Styles RA, Webb RJ (1989) Outcome of elective prostatectomy. BMJ 299:762-767

20. Roehrborn CG, Peters PC (1988) Can transabdominal ultrasound estimation of postvoiding residual (PVR) replace catheterization? Urology $31: 445-449$

21. Schäfer W (1990) Principles and clinical application of advanced urodynamic analysis of voiding function. Urol Clin North Am 17:553-566

22. Schröder FH, Blom JHM (1989) Natural history of benign prostatic hyperplasia (BPH). Prostate 2 [Suppl]: 17-22

23. Stoller ML, Millard RJ (1989) The accuracy of a catheterized residual urine. $\mathrm{J}$ Urol $141: 15-16$ 